\title{
Hip resurfacing in a district general hospital: 6-year clinical results using the ReCap hip resurfacing system
}

\author{
Walter van der Weegen ${ }^{1 *}$, Henk J Hoekstra', Thea Sijbesma', Shennah Austen ${ }^{1}$ and Rudolf W Poolman²
}

\begin{abstract}
Background: The purpose of our study was to prospectively report the clinical results of 280 consecutive hips (240 patients) who received a ReCap Hip Resurfacing System implant (Biomet Inc., Warsaw, USA) in a single district general hospital. Literature reports a large variation in clinical results between different resurfacing designs and published results using this particular design are scarce.

Methods: Mean follow up was 3.3 years (1.0 to 6.3) and four patients were lost to follow-up. All patients were diagnosed with end-stage hip osteoarthritis, their mean age was 54 years and $76.4 \%$ of all patients were male.

Results: There were 16 revisions and four patients reported a Harris Hip Score $<70$ points at their latest follow up. There were no pending revisions. Kaplan-Meier implant survival probability, with revision for any reason as endpoint, was 93.5\% at six years follow-up (95\%-Cl: 88.8-95.3). There were no revisions for Adverse Reactions to Metal Debris (ARMD) and no indications of ARMD in symptomatic non-revised patients, although diagnostics were limited to ultrasound scans.
\end{abstract}

Conclusions: This independent series confirms that hip resurfacing is a demanding procedure, and that implant survival of the ReCap hip resurfacing system is on a critical level in our series. In non-revised patients, reported outcomes are generally excellent.

Trial registration: ClinicalTrials.gov Identifier: NCT00603395

Keywords: Hip resurfacing, Implant survival, Adverse reaction to metal debris, ReCap design

\section{Background}

Hip resurfacing arthroplasty (HRA) has been widely used in recent years. Possible advantages of conserved femoral bone stock, low wear rates and low dislocation rates were the main reasons for surgeons to use HRA. Recent concerns on the use of Metal-on-Metal (MoM) bearings have intensified the discussion on HRA. The reported increase of metal ion levels after HRA with subsequent local Adverse Reactions to Metal Debris (ARMD) and poor results with revision for this complication have diminished the support for HRA [1-4].

In the published literature there is a wide range of clinical results between different HRA designs [3,5,6]. Although

\footnotetext{
* Correspondence: kog@st-anna.nl

'Department of Orthopaedic Surgery, St. Anna Hospital, Bogardeind 2Geldrop, EH 5664, Netherlands

Full list of author information is available at the end of the article
}

numeral clinical studies report short- and mid-term survival of different HRA systems, these studies focus on a limited number of HRA designs. To our knowledge, there are four studies published using the ReCap Hip Resurfacing System (Biomet Inc., Warsaw, USA). Gagala reported there were no significant complications after a maximum follow up (FU) of 20 months, using this implant design $(\mathrm{n}=23)$ [7]. Baad-Hansen reported no significant translation or rotation using this implant design $(n=25)$, after two year FU using radiostereometry (RSA) [8]. A larger number of ReCap procedures $(n=137)$ with a three year FU are described in the Australian National Joint Replacement Registry. In this report a cumulative percent revision rate of $7.6 \%$ is presented for this specific HRA design [9]. Recently, Gross and Liu presented the mid-term results of 740 hip resurfacings with a $3.4 \%$ revision rate [10].

\section{Biomed Central}

(c) 2012 van der Weegen et al.; licensee BioMed Central Ltd. This is an Open Access article distributed under the terms of the Creative Commons Attribution License (http://creativecommons.org/licenses/by/2.0), which permits unrestricted use, distribution, and reproduction in any medium, provided the original work is properly cited. 
In this prospective study, we report the clinical results of 280 consecutive HRA's using the ReCap Hip Resurfacing system, with a maximum FU of six years (range: 1-6). We hypothesised that implant survival would be compliant with the National Institute for Health and Clinical Excellence (NICE) benchmark (a revision rate of $10 \%$ or less at ten years, or consistent survival if only shorter FU is available) [11]. We further hypothesised that the risk for revision in subgroups based on gender, age and component size is comparable to findings in published literature.

\section{Methods}

\section{Patients}

Between September 2004 and September 2010 our first 280 consecutive, non-selected HRA procedures (240 patients) in a general district hospital were included in a prospective cohort study (Table 1 ).

Patients diagnosed with end stage osteoarthritis (OA) were indicated for HRA. The entire group involved 240 patients (280 resurfacings) with a mean follow-up of 3.3 years ( 1 to 6.3 ) of whom 45 were followed-up for five years and 30 for six years.

Prior to surgery, a dual energy X-ray absorptiometry (DEXA) scan was made of all female patients and in all male patients suspected of osteoporosis. When $\mathrm{T}$ and $\mathrm{Z}$ values were below normal, patients were excluded from HRA. After informing the patient on the expected benefits and risks associated with HRA, informed consent on the surgery procedure and on study participations was obtained from all patients. Our study was approved by the Institutional Review Board. Patients with renal failure, femoral cysts, osteoporosis or a-vascular necrosis $(\mathrm{AVN})$ of the femoral head were excluded. Female patients with a possible child wish were also excluded.

Table 1 Demographics of the study group

\begin{tabular}{lll}
\hline & Mean & Range \\
\hline Age at surgery (yr) & 54 & 28 to 76 \\
\hline BMl & 26.5 & 19 to 46 \\
\hline Hospital stay (days) & 3.5 & 2 to 9 \\
\hline Follow up (months) & 39 & 12 to 75 \\
\hline Sex $(\mathrm{n}=240$ patients) & Count & $\%$ \\
\hline Males & & \\
\hline Females & 187 & 77.9 \\
\hline Diagnosis ( $n=280$ hips) & 53 & 22.1 \\
\hline Primary OA & & \\
\hline DDH & 258 & 92.1 \\
\hline Posttraumatic OA & 19 & 1.1 \\
\hline OA indicates Osteartnis; DDH developm
\end{tabular}

OA indicates osteoarthritis; $D D H$, developmental dysplasia.

\section{Surgical technique and rehabilitation}

Two experienced joint arthroplasty surgeons (HJH, TS) used the ReCap Hip Resurfacing System (Biomet Inc, Warsaw, USA) in all patients in a standard manner. Prophylactic antibiotics were administered on induction. Both the press-fit acetabular component and the cemented femoral component are manufactured from "as-cast" cobalt chrome (Co-Cr-Mo) with a high carbon content $(>0.2 \%)$. The acetabular outside is a full-hemisphere design and has four pairs of fins for initial rotational stability. It has a titanium porous plasma spray surface coating (Figure 1). The outer geometry of the cemented femoral component extends approximately 23 degrees beyond a full-hemisphere. The critical inner bearing surface has a coverage arc ranging from 155-164 degrees from smallest to largest component.

The posterolateral approach was used in all procedures. After dislocating the hip joint, acetabular osteophytes were removed, the acetabulum was reamed and the acetabular component was impacted into the anatomical position. Next, a femoral guide wire was inserted into the femoral head, directed with a jig. The femoral head was then circumferentially reamed and the bone-bed was prepared with drill holes and pulse lavage for cementing. After applying high viscosity cement (Refobacin ${ }^{\circledR}$ Bone Cement R, Biomet Europe, Dordrecht, Netherlands) to the inner surface, the femoral component was carefully put in place.

Patients were mobilised the first post-operative day using two crutches and weight bearing as tolerated.

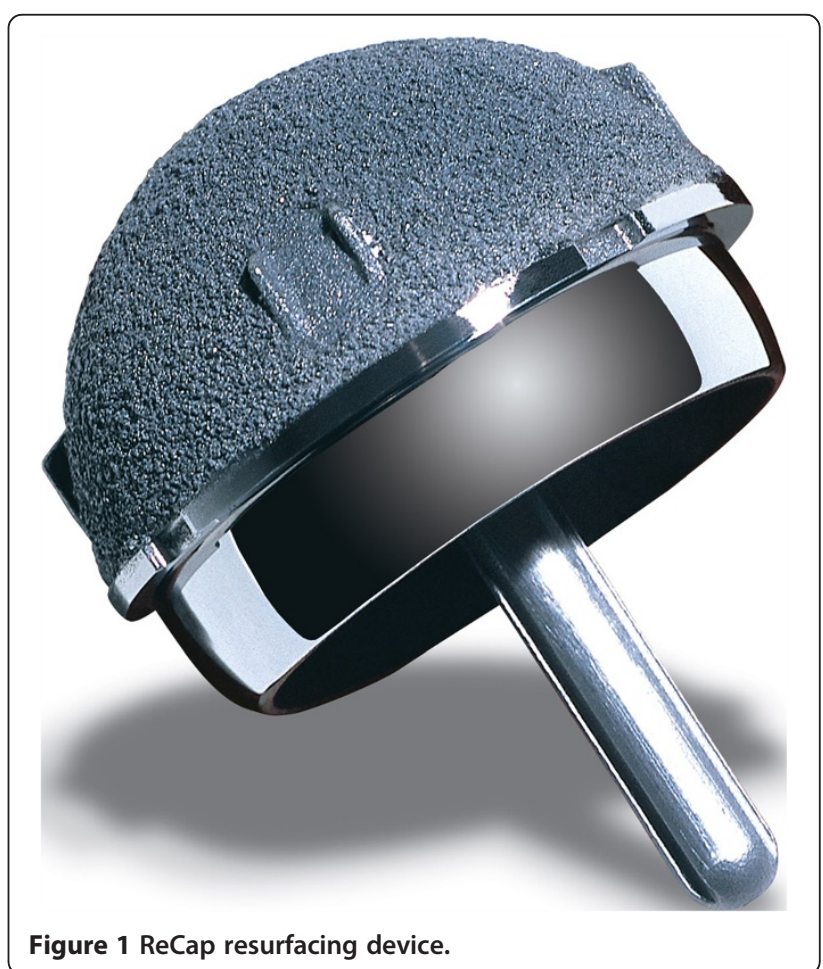


Patients were discharged if the patient was fully mobile and the wound was without problems. Physiotherapy was prescribed to all patients. Patients were instructed to avoid all high impact activities in the first six months and discouraged to participate in high impact sports. All bilateral procedures were staged interventions with at least a three months interval.

\section{Study protocol}

Patients were recruited at the time of surgery and prospectively followed six weeks after surgery and yearly thereafter. Bilateral cases were followed up as separate cases. Standard antero-posterior (AP) and lateral radiographs, and the Harris Hip Score [12] were collected at each visit, except for the six week FU. Only radiographs were collected at this visit. Any patient who was symptomatic post-operatively was analysed with a diagnostic ultrasound scan to check for ARMD.

On the plain anterio-posterior (AP) radiograph, the acetabular angle of inclination and femoral stem shaft angle were measured as described by Beaulé et al. [13]. Radiolucensies were measured in millimeters and acetabular radiolucency was classified in three zones according to DeLee and Charnley (Figure 2A) [14]. Any femoral radiolucencies were classified in the three zones as described by Beaulé et al. (Figure 2B) [13]. Heterotopic bone formation was classified as described by Brooker et al. [15]. Neck narrowing was measured as described by Grammatopoulos et al., using the first post operative radiograph and the most recent radiograph for comparison [16]. Clinical and radiological FU and statistical analyses were done by an independent observer, with a sample set of radiographic measurements audited by an experienced radiologist.

\section{Statistical analysis}

Revision for any reason was the primary endpoint of this study. Kaplan-Meier survivorship curves were calculated.
Since we support the recent notion in literature that implant survivorship is a limited endpoint to define a successful outcome for joint arthroplasty [17], a HHS score of $<70$ points on the latest FU (two years or more) was also used as an endpoint for implant failure. The NICE benchmark (a revision rate of $10 \%$ or less at ten years, or consistent survival if only shorter FU is available) was used to evaluate survivorship [11]. Relative risks (RR) were calculated to evaluate subgroup results based on gender, age, component size and acetabular inclination angle. A femoral head size $<50 \mathrm{~mm}$ and an acetabular inclination angle of $\geq 55^{\circ}$ were considered to be a risk factor for ARMD and therefore revision. [18-20] SPSS software (SPSS Statistics, version 17.0, IBM Corporation, Somers USA) was used for all statistical analyses. The occurrence of femoral neck narrowing as a consequence to head downsizing can also be indicative for ARMD, as described by Grammatopoulos et al. [16]. Neck narrowing values were calculated as a percentage and ranges were presented for the whole cohort and for the patients who were revised $>6$ months after index surgery.

\section{Results}

Four patients were deceased for reasons not related to the HRA procedure (four prostheses, 1.4\%) and no other patient was lost to FU. Three patients were contacted by phone since they were unable to return for FU. Therefore, radiological FU was complete for 277 patients. There were 16 revisions at the time of final FU. Seven were for fracture of the femoral neck, five for aseptic loosening of the acetabular component, two for component malpositioning (one femoral and one acetabular) and two for persistent pain (Table 2).

The Kaplan-Meier implant survival probability with revision for any reason as endpoint was $93.5 \%$ at six years

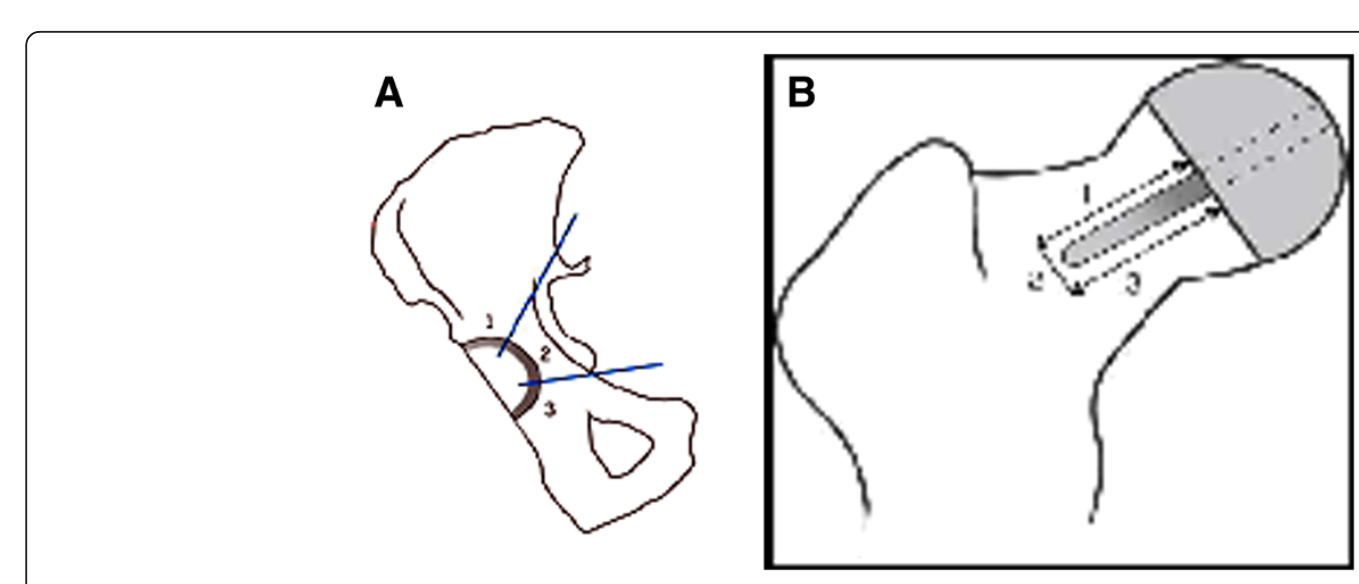

Figure 2 A: Acetabular radiolucency zones according to DeLee and Charnley [14]. B: Femoral radiolucency zones according to Beaulé [13]. 
Table 2 Revision details

\begin{tabular}{|c|c|c|c|c|c|}
\hline Failure mode & Gender & Age & Fem.comp. & Months to revision & Revision details \\
\hline FN\# & Male & 61 & $48 \mathrm{~mm}$ & 0.5 & Femoral revision \\
\hline FN\# & Female & 55 & $46 \mathrm{~mm}$ & 0.5 & Femoral revision \\
\hline FN\# & Male & 57 & $52 \mathrm{~mm}$ & 1 & Femoral revision \\
\hline$\overline{F N \#}$ & Male & 57 & $50 \mathrm{~mm}$ & 1 & Femoral revision \\
\hline FN\# & Male & 60 & $52 \mathrm{~mm}$ & 1 & Femoral revision \\
\hline FN\# & Male & 54 & $50 \mathrm{~mm}$ & 2 & Femoral revision \\
\hline$\overline{F N \#}$ & Male & 48 & $48 \mathrm{~mm}$ & 18 & Femoral revision \\
\hline Mal Fem Comp & Male & 60 & $52 \mathrm{~mm}$ & 0 & Both comp. revised \\
\hline Mal Acet Comp & Male & 67 & $50 \mathrm{~mm}$ & 12 & THP other hospital \\
\hline Asep Loosening & Male & 58 & $54 \mathrm{~mm}$ & 1 & Both comp.revised \\
\hline Asep Loosening & Male & 64 & $50 \mathrm{~mm}$ & 23 & Both comp. revised \\
\hline Asep Loosening & Female & 49 & $44 \mathrm{~mm}$ & 32 & Both comp.revised \\
\hline Asep Loosening & Male & 28 & $50 \mathrm{~mm}$ & 43 & Both comp.revised \\
\hline Asep Loosening & Female & 49 & $42 \mathrm{~mm}$ & 56 & Both comp.revised \\
\hline Persistent pain & Male & 43 & $50 \mathrm{~mm}$ & 7 & THP other hospital \\
\hline Persistent pain & Female & 52 & $50 \mathrm{~mm}$ & 27 & Both comp.revised \\
\hline
\end{tabular}

FN\# indicates fracture of the femoral neck; Mal Fem Comp: malpositioned femoral component; Mal Acet Com: malpositioned acetabular component; Asep Loosening: Aseptic loosening; Fem comp: femoral component size.

FU (95\%-CI: interval: 88.8-95.3) (Figure 3, table 3). The mean time to revision was 14 months (range: $0-56$ ) with eight out of 16 revisions within two months from index surgery. Female patients had a RR for revision of 1.1 compared to male patients (95\%-CI: 0.92-1.06). The RR for revision in the group of patients with a femoral head $<50 \mathrm{~mm}$, was 1.1 compared to the group of patients with larger components (95\%-CI: 0.98-1.09). In the patients younger 55 years the RR for revision was 0.9 compared to patients 55 years or older (95\%-CI: 0.95-1.07).

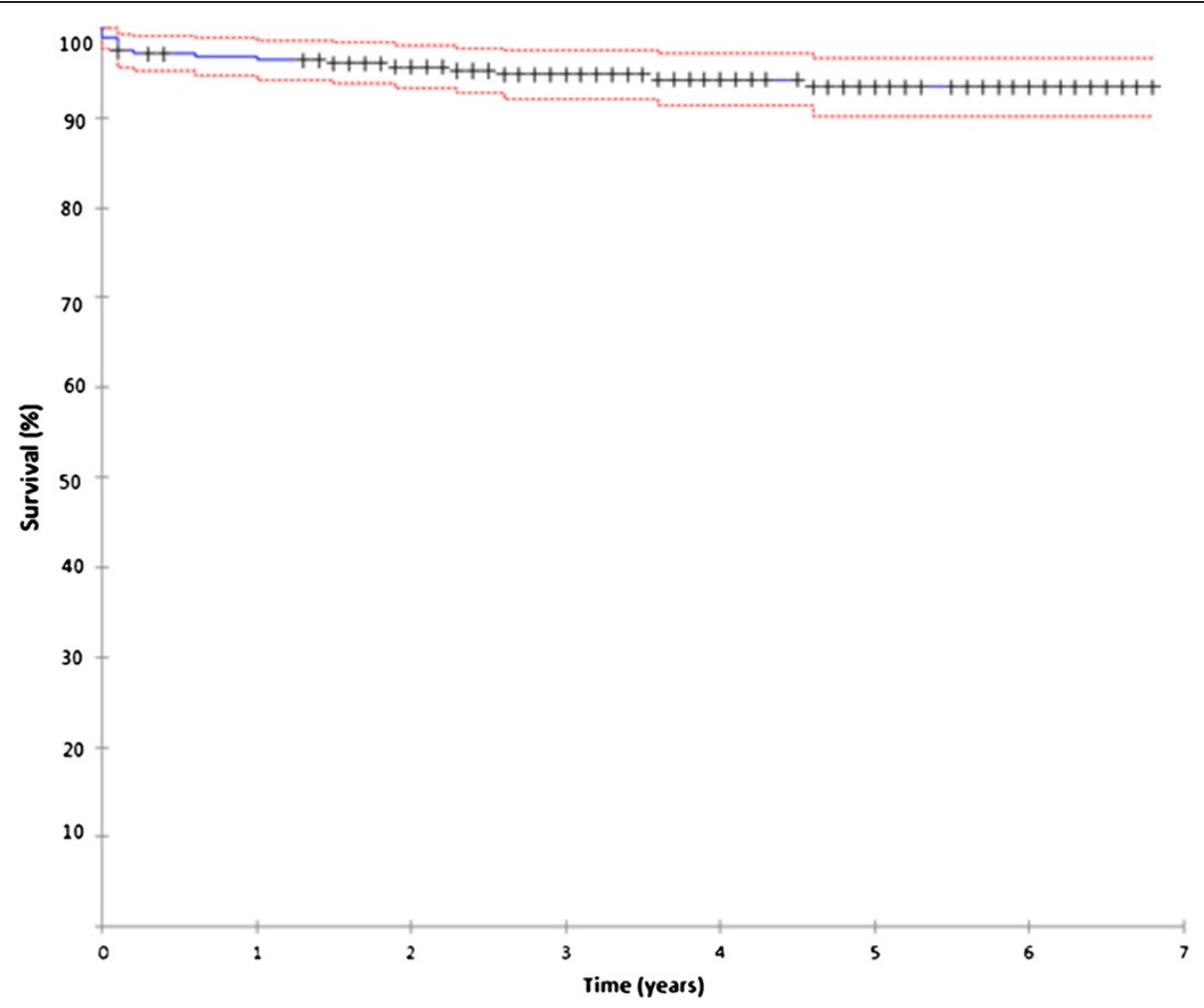

Figure 3 ReCap Kaplan-Meier implant survival probability. 
Table 3 Kaplan-Meier survival probability data details

\begin{tabular}{lcccccc}
\hline Year & Number of atstart & Failures & Withdrawn & Number of risk & Accumulated survival (\%) & 95\% Confidence interval \\
\hline 0 to 1 & 280 & 9 & 3 & 279.9 & 96.4 & 93.8 to 98.4 \\
\hline 1 to 2 & 259 & 3 & 24 & 257.0 & 95.7 & 92.4 to 97.6 \\
\hline 2 to 3 & 229 & 2 & 40 & 222.0 & 94.8 & 91.4 to 97.0 \\
\hline 3 to 4 & 185 & 1 & 48 & 176.0 & 94.3 & 90.7 to 96.6 \\
\hline 4 to 5 & 135 & 1 & 53 & 124.5 & 93.5 & 89.9 to 96.1 \\
\hline 5 to 6 & 80 & 0 & 43 & 75.5 & 98.5 & 89.9 to 96.1 \\
\hline 6 to 7 & 37 & 0 & 29 & 29.5 & 93.5 & 88.8 to 95.3 \\
\hline
\end{tabular}

\section{Revision details}

In all seven femoral neck fracture cases, the acetabular shell was left in situ and a stemmed, uncemented femoral prosthesis was inserted. Six out of seven neck fractures occurred within two months of the index surgery, one case was a late neck fracture 18 months post-operatively. During revision surgery of this one case it was observed that the femoral component was loose, which was thought to be caused by avascular necrosis of the femoral head. In all other cases both components were replaced. All cases of aseptic loosening only involved the uncemented acetabular component. Of the none-revised patients, there were four patients with a HHS score $<70$ points at their latest FU (two at two years and two at three years FU). Revision and clinical score combined as endpoint for implant failure, resulted in 20 failed prostheses at the time of final FU. During revision surgery no metallosis, soft tissue cysts or solid masses were observed, although postoperative histopathological analyses showed chronic inflammatory signs including synovial hyperplasia en some metallosis in both patients revised for persistent pain, indicating adverse local tissue reaction to metal debris. A diagnostic ultrasound was made in 27 patients (9.6\%) with unexplained hip or groin pains, all were normal. In our series there were 81 patients with an acetabular inclination angle of $55^{\circ}-65^{\circ}$ (of which 23 had a femoral head size $<50 \mathrm{~mm}$ ) and 10 patients with an acetabular inclination angle of $>65^{\circ}$ (of which four had a femoral head size $<50 \mathrm{~mm}$ ). In none of these patients any signs of ARMD were observed during any revision surgery or additional diagnostic ultrasound scans.

\section{Complications without need for revision}

There were 30 (10.7\%) complications without need for revision (Table 4 ).

The majority of these complications were transient such as post operative bleeding $(n=18)$. There was one deep wound infection which was eradicated after surgical debridement and antibiotic treatment. Seven other patients with signs of a post-operative wound infection were treated successfully with antibiotics. There was one patient with persistent paraesthesia and pareses of the foot due to an sciatic nerve lesion. One other patient had a transient nerve palsy of the sciatic nerve. Another patient was treated conservatively for a non-displaced fracture of the femoral neck, which he sustained due to a fall three months after surgery. He recovered without any persistent symptoms. A healed non-displaced femoral neck stress fracture was discovered with routine FU two years post-operatively (Figure $4 \mathrm{~A}$ and 4B). This patient had experienced some groin pain after running, which completely resolved when he did not run for a couple of weeks. There were no dislocations or thromboembolic events in our series.

\section{Outcomes}

At one year FU, mean HHS had improved significantly from pre-operative scores (from 49.3 to 92, $\mathrm{p}<0.0001$, Table 5).

At six year FU, 36 patients had an "excellent" HHS (66.7\%), 16 a "good" HHS (29.6\%) and two a "fair" HHS (3.7\%). For the revised patients, the mean HHS after revision was 77 (range 41-91).

\section{Radiological findings}

At one year FU, the mean implant femoral shaft angle was $135.1^{\circ}$ (range $116^{\circ}-156^{\circ}$ ). Mean acetabular angle of inclination was $51.3^{\circ}$ (range: $26^{\circ}-77^{\circ}$ ). With further FU, no radiolucensies were observed. Ectopic bone formation was noted in $13.8 \%$ of all cases. Mean HHS for patients who had a Brooker grade two or three ectopic bone formation was 91 points (range: 74-91) (Table 5). Neck narrowing was observed in 136 patients with a mean of $2.3 \%$ (range: $0 \%-18.5 \%$ ). In the patients with revisions later than 6 months after index surgery, neck narrowing was present in 3 out of 9 patients. One

Table 4 Complications without need for revision

\begin{tabular}{ll}
\hline Complication & N (\%) \\
\hline Nerve damage & $2(0.7 \%)$ \\
Non-displaced femoral neck fracture & $2(0.7 \%)$ \\
Deep wound infection & $1(0.4 \%)$ \\
Superficial wound infection & $7(2.5 \%)$ \\
Post-operative bleeding & $18(6.4 \%)$ \\
Total & $30(10.7 \%)$ \\
\hline
\end{tabular}



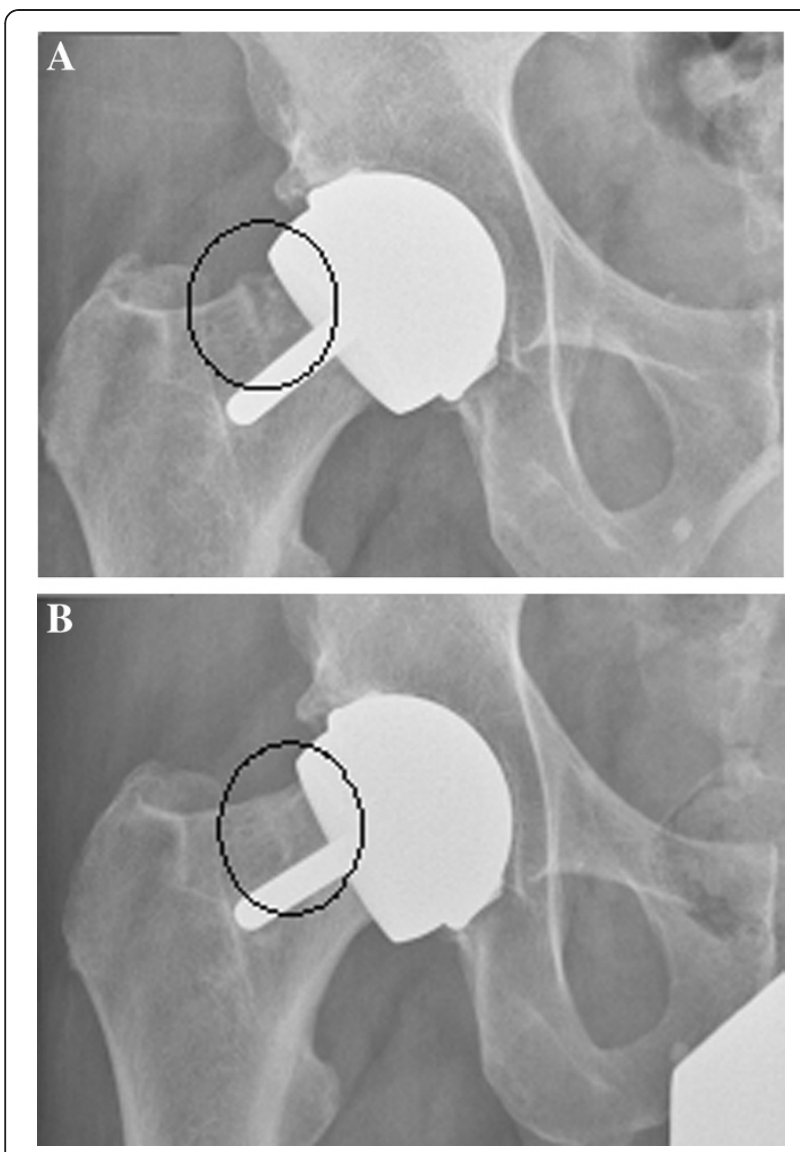

Figure 4 A: Non-displaced partial femoral neck fracture. B: Healed femoral neck fracture.

patient had $2.5 \%$ neck narrowing and two patients had $6 \%$ neck narrowing.

\section{Discussion}

Our KM-survival probability of $93.5 \%$ at six years FU (95\%-CI: 88.8-95.3) is not compliant with the three year entry NICE benchmark. Longer FU is needed to compare our results with the full 10-year benchmark. Of the non-revised patients, there were only four patients with implant failure based on their HHS score. The combined endpoints of revision $(n=16)$ and HHS score $<70$ points $(\mathrm{n}=4)$, resulted in 20 failed prosthesis (7.1\%). Since no other studies on MoM hip resurfacing have combined implant survival and Patient Reported Outcome scores to define implant performance, we cannot compare this result to other studies. We were able to identify all failure modes, including those from patients revised in other hospitals. Most frequent reasons for revision were fracture of the femoral neck $(n=7)$ and aseptic loosening $(n=5)$. All cases of aseptic loosening occurred relatively early and involved only the uncemented acetabular component. We think that insufficient seating of the acetabular component, which might occur due to deformation of the relatively thin cup during the impaction procedure, may have caused these early revision cases. In our series we have not observed any signs of ARMD during revision surgery, although post revision surgery two patients revised for persistent pain had histopathological evidence of adverse local tissue reaction (ALTR) to metal debris. Neither have we observed any signs of ARMD with diagnostic ultrasound scans in patients who were post-operatively symptomatic. We cannot completely rule out the presence of ARMD in our series, but since we observed two cases of ALTR, future follow-up will include routine metal ion analysis. Our complete FU, our detailed information on revision cases and the excellent clinical scores at the time of final FU are in contrast to other designs of HRA, of which failure rates of $25 \%$ for ARMD after six years FU are reported [21]. Risk factors for ARMD are the inclination angle of the acetabular cup, implant design, small component sizes and occurrence of neck narrowing. Steep inclination angles and an acetabular cup with less than hemispherical coverage result in a small contact patch area (CPA), which increases the wear rate. Another risk factor is component size, with small sizes resulting in more friction, releasing more metal debris [18-20]. In our series there were 81 patients with such risk factors, but no ARMD was observed in any of these patients, neither with a diagnostic ultrasound scan nor during revision surgery. The critical inner bearing surface of the ReCap has a coverage arc ranging from 155-164 degrees from smallest to largest component which is similar to other designs with a larger CPA such as the Birmingham Hip Resurfacing design (Smith and Nephew PLC, London, UK), the Conserve plus (Wright Medical Technology, Inc., Arlington, USA) and the Cormet

Table 5 Clinical and radiographic findings

\begin{tabular}{lllll}
\hline & HHS & Fem. Pos. & Cup abd. Angle & Brooker $\mathbf{1 / 2 / 3 / 4}(\mathbf{n})$ \\
\hline Pre op $(n=280)$ & 49.3 & $n / a$ & $n / a$ & $n / a$ \\
\hline 6 wks $(n=280)$ & - & $+2.2^{0}$ & $51.3^{0}$ & $13 / 2 / 0 / 0$ \\
\hline 1 yr $(n=280)$ & 92 & - & - & $29 / 7 / 2 / 0$ \\
\hline 2 yrs $(n=221)$ & 88.3 & - & - & $26 / 5 / 3 / 0$ \\
\hline 6 yrs $(n=54)$ & 89.3 & - & - & $11 / 3 / 1 / 0$ \\
\hline
\end{tabular}

HHS indicates mean Harris Hip Score; Fem. Pos, mean varus/valgus placement compared to anatomical femoral neck angle (+ indicates varus position); Cup abd. Angle, mean cup abduction angle; Br. 1/2/3/4, Ectopic Bone Formation classified as Brooker grade 1, 2, 3,4; Radioluc., Radiolucensies. 
resurfacing design (Corin Group PLC, Cirencester, UK). Our findings on ARMD are in line with several other studies. Malviya found a $0.15 \%$ incidence of pseudotumors using the Birmingham Hip Resurfacing (BHR) [22]. Beaulé et al. found a $0.1 \%$ prevalence of pseudotumors with MoM resurfacing after surveying nine Canadian Academic centers [23]. Glyn-Jones et al. extensively studied the risk factors for pseudotumor formation in a large series of hip resurfacings. Gender and age had a significant independent influence on the revision rate for pseudotumour formation, and the incidence increased with time, with a mean time to pseudotumour revision of 3.5 years (1 to 8.3 years) [24]. In the series presented by Steffen et al., there were three revision cases possibly related to metal debris. Two of these cases were revised around two years post-operatively, the other one at 5.6 years after surgery [25]. These mean times to pseudotumour revision are within the maximum follow-up time of our case series (6.3 years), but we will have to stay alert on ARMD occurrence with longer follow-up.

Grammatopoulos reported a mean 10.1\% neck narrowing in patients revised for pseudotumours. In our cohort the mean percentage of neck narrowing was considerably lower (2.3\%), although individual cases had greater neck narrowing. We did observe neck narrowing in three out of the nine patients who were revised> 6 months after index surgery, but these three patients had less than $10 \%$ neck narrowing. Neck narrowing data from our cohort is supplementary to the observations by Gross and Liu. They also report $<1 \%$ revisions for adverse wear and based on their report and on data from our cohort we believe that the risk for adverse wear using this resurfacing design is low. Gross did report a lower revision rate compared to our study (3.4\% versus $7.3 \%)$ but in his series the learning curve was avoided since the surgeon had performed 400 hip resurfacings before the presented series was started [10]. As noted in the study by Gross, we also now have begun recommending routine metal ion tests in all our patients.

Strong points of our study are its prospective study design, a large consecutive study cohort, limited lost to FU and comparison to an objective benchmark. There is detailed FU on all revised patients including those revised in other hospitals, and both clinical outcome scores and radiological FU were analysed. Another advantage is that this study was conducted in a general district hospital rather than a design institution. Our study also has limitations: FU time is limited and there is no control group. We also have to bear in mind that the NICE-benchmark is applied to an OA population of all ages, and literature describes higher revision rates in younger patients [26-28]. Metal-ion levels were not obtained and there were no diagnostic ultrasounds made to check for ARMD in non-symptomatic patients. Compared to published literature, our study reports the clinical results on more patients with longer FU using the ReCap Hip Resurfacing system than any other study. Gagala et al. studied 25 patients (mean FU 11 months, range: 10-20) and found good short-term clinical results without significant complications [7]. Baad-Hansen et al. conducted a radiostereometric analysis $(n=23)$. There was no statistically significant translation or rotation of the femoral component observed after two years FU [8]. The absence of any revisions in these series might be due to the small number of patients and the short FU. In the evaluation of risk factors for early failure with HRA, the Australian Arthroplasty Register reported on 137 procedures between 1999 and 2008 using the ReCap hip resurfacing system [9]. Their cumulative percent revision rate of $7.6 \%$ at three year FU using this system was worse than our implant survival at three years. A possible explanation might be that those 137 procedures were done by a large number of orthopedic surgeons in an extended period of time, limiting the individual expertise using this system. However, despite further enquiry, no more details could be provided by the Australian Arthroplasty Register.

Regarding patient selection, in our series the RR for revision was slightly higher for female and for older patients, although statistically the difference was not significant. Patients with smaller component sizes had a higher risk for revision, but this was also not statistically significant. This is in line with several other publications which show a significantly higher risk for revision in female patients, older patients, and in patients with small components [5,29-32]. The possible absence of ARMD in our series might explain the equal risk for revision in patients with small or large component sizes. Looking at diagnosis, literature reports that the best HRA results are obtained with OA [5,33]. In our series, only patients with this diagnosis were included.

\section{Conclusion}

Although implant survival rate in our series is below the NICE benchmark, patient reported outcomes are excellent in the non-revised patients. Also, we were not able to detect signs of ARMD with standard radiographs and clinical outcome scores. As with other resurfacing designs, this resurfacing system should be regarded as a difficult but effective surgical procedure for a small and specific patient population.

\section{Competing interests}

WvdW, HJH and TS are supported by benefits directed to a research fund from Biomet Inc.. SA declares no conflict of interest. RW P is supported by benefits directed to a research fund by Amgen, Lima, Link and Zimmer.

\section{Authors' contributions}

WvdW participated in the design of the study, data collection, analysis of the data, and drafting the manuscript. $\mathrm{HJH}$ participated in the design of the study, in data collection and drafting the manuscript. TS participated in the 
design of the study, in data collection and drafting the manuscript. SA participated in data collection and drafting the manuscript. RWP participated in drafting the manuscript. All authors read and approved the final manuscript.

\section{Acknowledgements}

The authors wish to thank Ellis Bos for her assistance in coordinating this study and help with data collection.

\section{Author details}

${ }^{1}$ Department of Orthopaedic Surgery, St. Anna Hospital, Bogardeind 2Geldrop, EH 5664, Netherlands. ${ }^{2}$ Department of Orthopaedic Surgery, Onze Lieve Vrouwe Gasthuis, Amsterdam, The Netherlands.

Received: 10 January 2012 Accepted: 7 December 2012

Published: 13 December 2012

\section{References}

1. Clarke MT, Lee PT, Arora A, Villar RN: Levels of metal ions after small- and large- diameter metal-on-metal hip arthroplasty. J Bone Joint Surg Br 2003, 85:913-917.

2. Delaunay C, Petit I, Learmonth ID, Oger P, Vendittoli PA: Metal-on-metal bearings total hip arthroplasty: the cobalt and chromium ions release concern. Orthop Traumatol Surg Res 2010, 96:894-904.

3. Langton DJ, Joyce TJ, Jameson SS, Lord J, Van Orsouw M, Holland JP, Nargol AV, De Smet KA: Adverse reaction to metal debris following hip resurfacing: the influence of component type, orientation and volumetric wear. J Bone Joint Surg Br 2011, 93:164-171.

4. Witzleb WC, Ziegler J, Krummenauer F, Neumeister V, Guenther KP: Exposure to chromium, cobalt and molybdenum from metal-on-metal total hip replacement and hip resurfacing arthroplasty. Acta Orthop 2006, 77:697-705.

5. Prosser GH, Yates PJ, Wood DJ, Graves SE, de Steiger RN, Miller LN: Outcome of primary resurfacing hip replacement: evaluation of risk factors for early revision. Acta Orthop 2010, 81:66-71.

6. van der Weegen W, Hoekstra HJ, Sijbesma T, Bos E, Schemitsch EH, Poolman RW: Survival of metal-on-metal hip resurfacing arthroplasty: a systematic review of the literature. J Bone Joint Surg Br 2011 93:298-306.

7. Gagała J, Mazurkiewicz T: First experiences with total hip resurfacing arthroplasty. Chir Narzadow Ruchu Ortop Pol 2007, 72:311-317. Article in Polish.

8. Baad-Hansen T, Storgaard Jakobsen S, Soballe K: Two-year migration results of the ReCap hip resurfacing system-a radiostereometric follow-up study of 23 hips. Int Orthop 2011, 35:497-502.

9. Hip and knee arthroplasty: annual report, 2010. Australian orthopaedic association, national joint registry.http://www.dmac.adelaide.edu.au/aoanjrr (date last accessed 27 June 2012)

10. Gross TP, Liu F: Hip resurfacing with the Biomet hybrid ReCap-magnum system: 7-year results. J Arthroplasty 2012, [Epub ahead of print].

11. National institute for clinical excellence (NICE). guidance on the selection of primary total hip replacement. London 2003. http://www.nice.org.uk (date last accessed 25 June 2012).

12. Harris WH: Traumatic arthritis of the hip after dislocation and acetabula fractures: treatment by mold arthroplasty. An end-result study using a new method of result evaluation. J Bone Joint Surg Am 1969, 51:737-755.

13. Beaulé PE, Dorey FJ, LeDuff M, Gruen T, Amstutz HC: Risk factors affecting outcome of metal-on-metal surface arthroplasty of the hip. Clin Orthop Relat Res 2004, 418:87-93.

14. DeLee JG, Charnley J: Radiological demarcation of cemented sockets in total hip replacement. Clin Orthop 1976, 121:20-32.

15. Brooker AF, Bowerman JW, Robinson RA, Riley LH Jr: Ectopic ossification following total hip replacement. Incidence and a method of classification. J Bone Joint Surg Am 1973, 55:1629-1632.

16. Grammatopoulos G, Pandit H, Oxford Hip and Knee Group, Murray DW, Gill HS: The relationship between head-neck ratio and pseudotumour formation in metal-on-metal resurfacing arthroplasty of the hip. J Bone Joint Surg Br 2010, 92:1527-1534.

17. Wylde V, Blom AW: The failure of survivorship. J Bone Joint Surg Br 2011, 93:569-570.
18. De Haan R, Pattyn C, Gill HS, Murray DW, Campbell PA, De Smet K: Correlation between inclination of the acetabular component and metal ion levels in metal-on-metal hip resurfacing replacement. J Bone Joint Surg Br 2008, 90:1291-1297. Erratum in: J Bone Joint Surg Br 2009, 91:700.

19. Hart AJ, Buddhdev P, Winship P, Faria N, Powell JJ, Skinner JA: Cup inclination angle of greater than 50 degrees increases whole blood concentrations of cobalt and chromium ions after metal-on-metal hip resurfacing. Hip Int 2008, 18:212-219.

20. Desy NM, Bergeron SG, Petit A, Huk OL, Antoniou J: Surgical variables influence metal ion levels after hip resurfacing. Clin Orthop Relat Res 2011, 469:1635-1641.

21. Langton DJ J, Jameson SS, Joyce TJ, Gandhi JN, Sidaginamale R, Mereddy P, Lord J, Nargol AV: Accelerating failure rate of the ASR total hip replacement. J Bone Joint Surg Br 2011, 93:1011-1016.

22. Malviya A, Holland JP: Pseudotumours associated with metal-on-metal hip resurfacing: 10-year Newcastle experience. Acta Orthop Belg 2009, 75:477-483.

23. Beaulé PE, Kim PR, Powell J, Mackenzie J, Werle J, Antoniou J, Huk O, Vendittoli PA, Lavigne M, Smith F, Naudie D, McCalden R, Bourne R, Schemitsch E, Garbuz D, Greidanus N, Duncan C, Belzile E: A survey on the prevalence of pseudotumors with metal-on-metal hip resurfacing in Canadian academic centers. J Bone Joint Surg Am 2011, 93:118-121.

24. Glyn-Jones S, Pandit H, Kwon YM, Doll H, Gill HS, Murray DW: Risk factors for inflammatory pseudotumour formation following hip resurfacing. J Bone Joint Surg Br 2009, 91:1566-1574.

25. Steffen RT, Pandit HP, Palan J, Beard DJ, Gundle R, McLardy-Smith P, Murray DW, Gill HS: The five-year results of the Birmingham Hip Resurfacing arthroplasty: an independent series. J Bone Joint Surg Br 2008, 90:436-441.

26. Berry DJ, Harmsen WS, Cabanela ME, Morrey BF: Twenty-five-year survivorship of two thousand consecutive primary charnley total hip replacements: factors affecting survivorship of acetabular and femoral components. J Bone Joint Surg Am 2002, 84:171-177.

27. Corten K, Bourne RB, Charron KD, Au K, Rorabeck CH: What works best, a cemented or cementless primary total hip arthroplasty? minimum 17year followup of a randomized controlled trial. Clin Orthop Relat Res 2011, 469:209-217.

28. National joint registry for England and Wales: 7th annual report. 2010. http://www.njr.centre.org.uk/njrcentre/AbouttheNJR/Publications and reports/Annualreports/tabid/86/Defaultapx (date last accessed 30 may 2012)

29. Jameson SS, Langton DJ, Natu S, Nargol TV: The influence of age and sex on early clinical results after hip resurfacing: an independent center analysis. J Arthroplasty 2008, 23:50-55.

30. Kim PR, Beaulé PE, Laflamme GY, Dunbar M: Causes of early failure in a multicenter clinical trial of hip resurfacing. J Arthroplasty 2008, 23:44-49.

31. Corten $\mathrm{K}, \mathrm{MacDonald} \mathrm{SJ}$ : Hip resurfacing data from national joint registries: what do they tell us? what do they not tell us? Clin Orthop Relat Res 2010, 468:351-357.

32. Shimmin AJ, Walter WL, Esposito C: The influence of the size of the component on the outcome of resurfacing arthroplasty of the hip: a review of the literature. J Bone Joint Surg Br 2010, 92:469-476.

33. Schmalzried TP, Silva M, de la Rosa MA, Choi ES, Fowble VA: Optimizing patient selection and outcomes with total hip resurfacing. Clin Orthop Relat Res 2005, 441:200-204.

\section{doi:10.1186/1471-2474-13-247}

Cite this article as: van der Weegen et al:: Hip resurfacing in a district general hospital: 6-year clinical results using the ReCap hip resurfacing system. BMC Musculoskeletal Disorders 2012 13:247. 